\title{
ALGUNAS CONSIDERACIONES EN TORNO AL DERECHO FUNDAMENTAL A LA PARTICIPACIÓN DIRECTA EN LOS ASUNTOS PÚBLICOS
}

\author{
NICOLÁS PÉREZ SOLA \\ Profesor Titular de Derecho Constitucional
}

Universidad de Jaén 


\section{SUMARIO}

1. INTRODUCCIÓN.-2. LA UBICACIÓN DE LA PARTICIPACIÓN EN LA DEFINICIÓN DEL ESTADO. - 3. LA PARTICIPACIÓN POLITICA COMO DERECHO FUNDAMENTAL.-4. LA PARTICIPACIÓN COMO PRINCIPIO ORIENTADOR DE LA ACCIÓN DEL ESTADO.-5. LA DIFICIL CONFIGURACIÓN DE UN DERECHO A LA PARTICIPACIÓN POLITICA DIRECTA DE LOS CIUDADANOS. 
Revista de Derecho Político, núm. 41, 1996, pp. 97-118

\title{
ALGUNAS CONSIDERACIONES EN TORNO AL DERECHO FUNDAMENTAL A LA PARTICIPACIÓN DIRECTA EN LOS ASUNTOS PÚBLICOS
}

POR

\author{
NICOLÁS PÉREZ SOLA \\ Profesor Titular de Derecho Constitucional \\ Universidad de Jaén
}

\section{INTRODUCCIÓN}

La constitucionalización de una pluralidad de instrumentos que posibiliten la participación de los ciudadanos en los asuntos públicos constituye un elemento esencial de nuestro sistema político democrático. Ahora bien, la concreción en el artículo 23 CE de una doble vía participativa conlleva necesariamente la coexistencia de diversas formas de participación ciudadana junto a las instituciones propias del sistema representativo. Este reconocimiento encuentra su causa en la democraticidad del Estado, si bien resulta indudable que con el advenimiento del Estado social y el reconocimiento de nuevos derechos a los ciudadanos, ha recibido un fuerte impulso el fenómeno participativo. Es a partir de aquí que se han instrumentado nuevas formas de participación ciudadana más allá de los tradicionales cauces políticos y que permite, bien a título individual, bien a través de grupos organizados (de forma permanente o no, para la satisfacción de sus intereses), esferas y cauces de participación ya inter-particulares, ya en las relaciones entre particulares y poderes públicos, cuyos límites resultan por el momento difícil de predecir.

Ahora bien, la proclamación de la soberanía nacional residenciada en el pueblo español (art. 1.2 CE) no constituye una afirmación de partida incontrovertible. Desde una lectura meramente descriptiva de nuestra Norma Fundamental, se evidencia cierta contradicción entre la anterior 
aseveración y la exclusión del ciudadano de instituciones como la iniciativa de reforma constitucional. Pero más allá de esta concepción del ciudadano capitidisminuido en el ámbito del poder constituido, que se podría engrosar con el carácter facultativo del referéndum constitucional en el procedimiento de reforma ordinario (art. $167 \mathrm{CE}$ ), es notorio que la participación directa del ciudadano en los asuntos públicos (art. 23.1 CE) queda constreñida a la constitucionalización de determinados procedimientos cuyo desarrollo normativo corresponde al legislador. En efecto, el referéndum en sus diversas modalidades, la iniciativa legislativa popular así como el derecho de petición no son más que los derechos de configuración legal en que se materializa la participación directa de los ciudadanos. Además podemos recordar cómo la regulación de aquéllos operada por el legislador orgánico en desarrollo de los preceptos constitucionales, no sólo limita su alcance y contenido (referéndum e iniciativa legislativa popular), sino que desvirtúa en algunos casos la esencia de la institución (referéndum consultivo).

Pero también es cierto, como ya queda apuntado, que la constitucionalización tanto de nuevos derechos como la aparición de ámbitos hasta no hace mucho vedados a la participación de los ciudadanos, dota a la CE de una virtualidad que, lejos de agotarse con su ejercicio inmediato, cobra su verdadera dimensión en la medida en que constituye un horizonte esperanzador para la superación del cada día mayor déficit democrático de los Estados modernos. En este sentido qué duda cabe que la participación del ciudadano en la Administración (art. $105 \mathrm{CE}$ ) y, de modo singular, en la Administración de Justicia (art. $125 \mathrm{CE}$ ), supone la ampliación considerable de los tradicionales ámbitos de participación política de los titulares de la soberanía. Sin embargo, una visión somera de la experiencia obtenida tras trece años de régimen democrático no llega a satisfacer los controles más exigentes de efectividad de la participación directa del ciudadano en la vida política del Estado.

\section{LA UBICACIÓN DE LA PARTICIPACIÓN EN LA DEFINICIÓN DEL ESTADO}

El diseño teórico de la participación del ciudadano en los asuntos públicos contenido en la CE de 1978 requiere algunas concreciones sistematizadoras al menos, al solo efecto de su ubicación, dentro del esquema institucional contenido en nuestra Norma Suprema. Asi, de los diversos instrumentos participativos constitucionalizados, podremos extraer algunas consideraciones respecto a la filosofía "participativa" que se contiene en aquélla. 
No cabe duda que la proclamación de la democraticidad del Estado español contenida en el artículo 1.1 del texto constitucional, junto al pluralismo político como valor superior del ordenamiento jurídico, suponen la formulación de la participación como requisito indiscutible de todo régimen democrático. De este modo, si se predica de la democracia el ser "principio legitimador de la política de nuestro siglo" ', la participación constituye un elemento esencial de aquélla, definida "en el sentido de un sistema de participación en la elaboración de las decisiones y de participación en la que los ciudadanos desempeñen de alguna manera un papel activo" ${ }^{2}$. La articulación que posteriormente se haga de la participación no cuestiona en absoluto la anterior afirmación. Sólo desde un marco participativo de pluralismo político es concebible la existencia democrática en un Estado. A partir de entonces estaremos en condiciones de analizar el tratamiento constitucional que se le dispensa en sus diversas manifestaciones, a la participación política del ciudadano y sus relaciones con el resto del esquema participativo contenido en nuestra Ley Fundamental.

El punto de partida ineludible lo constituye la proclamación contenida en el artículo 1.1 CE del carácter social y democrático de derecho del Estado español. Es, pues, una primera afirmación que, lejos de limitarse a un afán programático, tiene su correspondiente concreción en diversos apartados del texto. La definición del Estado se ubica en la misma línea que las Constituciones de las democracias europeas de postguerra y pretende recoger claramente una concepción a la par descriptiva e integradora de las distintas fases del Estado moderno. En este sentido se ha pronunciado el Tribunal Constitucional (en adelante TC) indicando cómo "la Constitución (...), al establecer en su artículo 1.1 la norma que configura al Estado como social y democrático de Derecho, está afirmando un principio que se ajusta a una realidad propia del mundo occidental de nuestra época, y que trasciende a todo el orden jurídico" ${ }^{3}$. Sin embargo, no constituye el objeto del presente estudio el análisis de cuál ha de ser la interpretación correcta del establecimiento de "una sociedad democrática avanzada" contenida en el Preámbulo de la Constitución y que ha sido ampliamente tratado en la doctrina. Baste reseñar aquí una de las posiciones sustentadas sobre el carácter dinámico de tal declaración: así, LUCAS VERDÚ ${ }^{4}$ ha señalado cómo pese a carecer de aplicación inmediata la cláusula de sociedad democrática avanzada, ésta actúa como "valor jurídico interpretativo y valorativo" del que se desprende tanto un "valor impeditivo como impositivon.

M. Ramírez, La Participación Política, Madrid, 1985, pág. 27.

Ibidem, pág. 30.

STC 18/1984, de 7 de febrero, BJC 35, pág. 370.

P. Lucas Verdú, Curso de Derecho Político, Madrid, 1984, pág. 450. 
Se comprende, pues, que a partir de la definición del Estado como democrático, el reconocimiento del pueblo como soberano constituya la consecuencia lógica del principio democrático. Principio fundamental en todo el diseño político institucional de nuestra Constitución que, como ha indicado ARAGÓN REYES ${ }^{5}$, «se proyecta en la totalidad de nuestro orden estatal por ser precisamente el punto nuclear que lo articula, que le da forma, que define la forma del Estado". Queda así reafirmado el carácter "más fundamental» del principio democrático respecto del resto de los principios generales del ordenamiento, pero, precisamente de esta condición, deviene su generalidad que obliga "para intervenir en el ordenamiento, de ciertas conexiones" que consisten en "situar el principio en los distintos niveles o momentos en que jurídicamente opera, así como indagar la dimensión del principio que en cada uno de esos momentos se despliegan ${ }^{6}$. En este sentido otros preceptos complementan tal proclamación: el reconocimiento del sufragio universal (art. 68.1 CE), las Cortes Generales como representantes del pueblo español (art. $66 \mathrm{CE}$ ), la justicia que emana del pueblo (art. $117 \mathrm{CE}$ ), las Asambleas Legislativas de las Comunidades Autónomas elegidas por sufragio universal (art. 152.1 CE) y la sanción popular de la reforma agravada de la Constitución (art. 168.3 CE).

Por su parte la ubicación de la soberanía en el pueblo otorga una ineludible legitimación a todo el sistema político que disipa cualquier duda respecto a su origen como a sus parámetros esenciales'. Así la interacción del principio democrático y la titularidad por "el pueblo español» de la soberanía produce "una respuesta normativa al problema de la legitimación política en el plano material y formal ${ }^{8}$. En cualquier caso, no

5 M. Aragón Reyes, Constitución y Democracia, Madrid, 1989, pág. 19.

- Ibidem, pág. 101.

7 A. Pizzorusso ha señalado cómo «el alcance básico de la soberanía popular es que corresponde al pueblo expresar las orientaciones fundamentales en cuyo marco habrá de comprenderse la procura de los intereses públicos, sin prejuzgar por ello, de modo rígido y cerrado, cuáles puedan ser las formas a través de las que pueda realizarse este empeñon. Lecciones de Derecho Constitucional, Madrid, 1984, pág. 104.

a A. Pérez Luño, Derechos Humanos, Estado de Derecho y Constitución, Madrid, 1984, pág. 20. Concreta este autor la irradiación del principio democrático en ambos planos: «El primero porque condiciona la legitimación constitucional del poder a la participación política de los ciudadanos, al respeto de sus derechos fundamentales $y$ al reconocimiento del pluralismo de iniciativas $y$ alternativas sociales. En el segundo porque representa simultáneamente una fórmula de racionalización del proceso político y una forma de limitación del poder estatal". También ARAGón REYES, "La Monarquía parlamentaria", en Predieri, A., y G. Enterría (eds.), La Constitución española de 1978. Estudio sistemático, ha señalado cómo "partiendo de un concepto de nación como el que se ha visto, no se otorga a la nación la soberanía, 
es absolutamente pacífica la interpretación del apartado 2.ำ del artículo 1. Parece evidente que se deja notar la influencia del artículo 3 de la Constitución francesa de 1958; pero allí tenía sentido mantener la concepción nacional de la soberanía en correspondencia a su tradición jurídica, mientras que en nuestro ordenamiento no encaja del todo ${ }^{9}$. Pese al intento integrador formulado desde la doctrina ${ }^{10}$, parece evidente que de la redacción del artículo 1.2 se desprende "la interesada falta de imaginación de que el sistema representativo hace gala cuando se trata de idear soluciones que permitan vitalizar la posición política de los ciudadanos, lo que es más, la beligerante rotundidad con que, llegado el caso, tales soluciones (...) son rechazadas" ".

Ahora bien, la proclamación de un lado de la democraticidad del Estado y, de otra parte, del pueblo como soberano requieren una mayor concreción y aproximación. En efecto, resulta, pues, obligada la referencia a determinados preceptos que a través fundamentalmente de los artículos $6,9.2$ y $23.1 \mathrm{CE}$, encuentran su desarrollo ${ }^{12}$, toda vez que en búsqueda de una visión global del sistema participativo se hace preciso delimitar, dentro del campo participativo, la intervención de los ciudadanos en la adopción de decisiones, del resto de ámbitos en los que constitucionalmente se les reconoce capacidad para intervernir. Sin perjuicio de afrontar la correcta interpretación del término asuntos públicos, inicialmente más avocado a la confusión que a clarificar su alcance.

sino que la soberanía nacional se atribuye al pueblo. La nación no es el pueblo, es la patria, pero únicamente el pueblo puede expresar la voluntad de la nación (...). Se trata de una monarquía parlamentaria, lo que significará, de modo inevitable, que todos los poderes del Estado emanan del pueblo. Triunfa así el principio democrático sin renunciar a la simbología del principio monárquico" (pág. 451).

- Como ha señalado A. Garrorena Morales (El Estado Español como Estado social $y$ democrático de derecho, Madrid, 1984), "la fórmula del artículo 1.2 (...), que no es precisamente un dechado de rigor y calidad técnica, ha mixturado contundentemente varias de esas representaciones" (pág. 124).

10 Desde otra perspectiva, el profesor P. LuCAs Verdú entiende que "la reducción constitucional de la antinomia (soberanía nacional-soberanía popular) convirtiéndola en síntesis, es significativa porque confirma, también, la síntesis entre el reformismo y el rupturismo dentro del precepto que realiza la refundación del Estado". "Comentario al artículo 1", en O. Alzaga, Comentario a las Leyes Políticas, pág. 171.

A. Garrorena Morales, op. cit., pág. 128.

12 Sin embargo, como ha señalado E. Álvarez CONDE (El régimen político español, Madrid, 1985), "resulta difícil, por no decir imposible, encontrar manifestaciones concretas de esta proclamación constitucional, ya que ni siquiera preceptos como el artículo 9.2 o el 129.2 parecen adecuarse a estos esquemas. Quizá el único indicio al respecto se encuentra en el Preámbulo", (pág. 48). 
Como proclamación de carácter general, los artículos 23.1 y 9.2 constituyen los parámetros que enmarcan el desarrollo último de la democracia en el Estado español en aras de su "profundización" contenida en el Preámbulo. Ambos preceptos son coincidentes en la medida en que inciden en la participación de los ciudadanos, si bien la perspectiva que se contiene en cada uno es diversa.

\section{LA PARTICIPACIÓN POLÍTICA COMO DERECHO FUNDAMENTAL (ARTÍCULO 23.1 CE)}

En el artículo 23 CE se contiene el reconocimiento del derecho a la participación "en los asuntos públicos, directamente o por medio de representantes", así como a "acceder en condiciones de igualdad a las funciones y cargos públicos". La "íntima conexión de los dos apartados" ${ }^{13}$ ha sido reconocida por el TC, que ha señalado cómo "el derecho de sufragio activo y el pasivo son aspectos indisociables de una misma institución, nervio y sustento de la democracia" ${ }^{14}$. Sin embargo, se trata de dos apartados de distinto contenido y que requieren un análisis separado. Como comprobaremos después, el constituyente debía resolver qué modelo de participación habría de ser el prioritario o preferencial de entre las "distintas formas participativas" ${ }^{15}$ que previsiblemente se contendrían en la Constitución del 1978. Pues bien, en el artículo 23.1 CE se está reconociendo la participación como derecho fundamental integrado en un sistema jurídico que garantiza la protección del mismo (art. $53 \mathrm{CE}$ ), que se engloba dentro de un conjunto de materias protegidas por un procedimiento de reforma superagravado (art. $168 \mathrm{CE}$ ) y el amparo de la jurisdicción constitucional. No estamos, pues, ante una simple declaración de un derecho recogido en la Constitución, sino ante "la auténtica vertiente subjetivizada de toda la estructura democrática del Estado" ${ }^{16}$. En este sentido, como ha indicado AGUIAR DE LUQUE, "el artículo 23.1 puede ser considerado como la concreción a nivel de derecho subjetivo del principio participativo que en el 9.2 se consagra como uno de los fines por excelencia de los poderes públicos».

13 STC 5/1983, de 4 de febrero, BJC 23, pág. 234.

${ }_{14}$ En este sentido la STC 24/1990, de 15 de febrero, BJC 107, pág. 86.

15 M. Ramírez, op. cit., pág. 51.

15 J. A. Santamaria, "Comentario al artículo 23 ", en Garrido Falla, F. (dir.), Comentarios a la Constitución, op. cit., pág. 443.

17 L. Aguiar de Luoue, "Comentario al artículo 23", en O. Alzaga (dir.), Comentario a las Leyes Políticas, op. cit., pág. 659. 
Por tanto, el artículo $23 \mathrm{CE}$ recoge dos manifestaciones tradicionales del derecho de participación en los asuntos públicos que identificamos con la participación política "directamente o por representante», con la condición común de que este derecho se dirija a "los asuntos públicos", acepción ésta que nos permite llevar a cabo la anterior identidad pero que no resuelve ni el sentido correcto en que hemos de interpretar tales asuntos ${ }^{18}$, ni tampoco si éstos se circunscriben al ámbito político en sentido estricto. En cierta medida la jurisprudencia constitucional ha contribuido a deslindar el alcance de dicho precepto al considerar que alcanzaría no sólo a los cargos y funciones representativas a través de procedimientos electivos, sino también a los cargos y funciones de otro orden, siempre, claro está, que se trate de cargos y funciones públicos ${ }^{19}$. Se posibilita de este modo una comprensión amplia de la participación en los asuntos públicos que excede del procedimiento electoral selectivo pero no admite una acepción más sociológica de la política. El recurso a la voluntas legislatoris del constituyente no deja lugar a dudas, se trata exclusivamente de una genérica referencia a la participación política, en la que únicamente está presente el reconocimiento constitucional al derecho de participación circunscrito al ámbito institucional del Estado. Aun cuando la anterior afirmación pueda modularse en función de ámbitos específicos que de una u otra manera el propio texto constitucional contempla, parece indiscutible que el derecho a la participación queda circunscrito al ámbito político y no a otras manifestaciones de la vida socioeconómica y cultural que se contienen en el artículo 9.2 CE. Por tanto la concreción de la participación en los asuntos públicos pasa por su identificación con la participación en la vida política, en la toma de decisiones políticas $y$, en la selección de los interlocutores políticos. En cualquier caso no es gratuita la necesidad de acotar la expresión "asuntos públicos» en favor de los ámbitos de toma de decisiones políticas con exclusión de otras esferas de los Estados modernos; se justifica así, además, que los principios rectores sólo informen el ordenamiento jurídico.

Efectuado este primer deslinde, conviene ahora concretar el derecho de participación directa a través de algunas precisiones. Como muy tempranamente señaló nuestro Alto Tribunal, el derecho de participación

18 J. A. Santamaria, "Comentario al artículo 23", en Garrido Falla, F. (dir.), Comentarios a la Constitución, op. cit, pág. 444.

${ }_{19}$ STC 24/1990, de 15 de febrero de 1990, BJC 107, pág. 85. Añadiendo a continuación nuestro Alto Tribunal cómo «esta extensión del ámbito protegido por el derecho fundamental no implica, sin embargo, en modo alguno, que dentro de él no hayan de establecerse distinciones, pues no es el mismo el contenido de tal derecho cuando se predica de cargos funcionariales o, más ampliamente, no representativos, que cuando hace relación a cargos que se alcanzan a través de la elección popular y tienen, por tanto, naturaleza representativa". 
como derecho fundamental goza del «doble carácter que tienen los derechos fundamentales. En primer lugar, los derechos fundamentales son derechos subjetivos, derechos de los individuos no sólo en cuanto derechos de los ciudadanos en sentido estricto, sino en cuanto garantizan un status jurídico o la libertad en un ámbito de la existencia. Pero al propio tiempo, son elementos esenciales de un ordenamiento objetivo de la comunidad nacional, en cuanto ésta se configura como marco de una convivencia humana justa y pacífica, plasmada históricamente en el Estado de Derecho y, más tarde, en el Estado social de Derecho o el Estado social y democrático de Derecho, según la fórmula de nuestra Constitución (artículo 1.1) ${ }^{20}$. Además, la virtualidad de la constitucionalización de la participación política queda garantizada plenamente, como ha señalado el TC respecto a la remisión a ley orgánica que se contiene en algunos preceptos de la CE para el desarrollo de los derechos fundamentales: "No tiene el significado de diferir la aplicación de los derechos fundamentales y libertades públicas hasta el momento en que se dicte una Ley posterior a la Constitución, ya que en todo caso sus principios son de aplicación inmediata" ${ }^{21}$.

Sin embargo, fácilmente se puede detectar una cierta contradicción interna en el propio Texto Constitucional, toda vez que los mecanismos a través de los que puede llevarse a cabo la participación directa de los ciudadanos, están sujetos a previo desarrollo normativo (arts. 29.1, 87.3, 92.3 y 151.1 CE). Extremo éste que obliga a la búsqueda de la correcta interpretación del sentido que se deba otorgar al artículo $23.1 \mathrm{CE}$. Resulta por tanto conveniente intentar delimitar el alcance y contenido de este precepto, así como los límites concretos del derecho de participación en los asuntos públicos.

Dada la íntima conexión de la participación política con la vocación democrática del Estado, cabría postular la centralidad de este precepto en la estructura constitucional, si bien sólo podemos deducir con carácter general, el protagonismo incuestionable de los partidos políticos en nuestro sistema constitucional. De suerte que la participación del ciuda-

20 STC 25/1981, de 14 de Julio, BJC 5, pág. 331.

${ }^{21}$ STC 18/1981, BJC 3. Prevalencia de este derecho fundamental que se ha puesto de manifiesto, entre otras, en la STC 119/1990, de 21 de junio (BJC 111), de tal modo que, según este último pronunciamiento, "no resulta congruente una interpretación de la obligación de prestar acatamiento a la Constitución que antepone un formalismo rígido a toda otra consideración, porque de ese modo se violenta la misma Constitución de cuyo acatamiento se trata, se olvida el mayor valor de los derechos fundamentales (en concreto, los del art. 23) y se hace prevalecer una interpretación de la Constitución excluyente frente a otra integradora" (pág. 147). 
dano en los asuntos públicos difiere en función de la existencia o ausencia de mediación ("por representante») en el ejercicio del derecho. Pues aun cuando la titularidad del mismo corresponde al ciudadano, su ejercicio admite la intermediación de modo tal que es el partido o formación política quien a través de la representación conforma en la mayoría de las ocasiones la voluntad general. A partir de ahí, con una descripción lineal del derecho de participación, podríamos indicar cómo en el ejercicio directo del mismo la formación de la voluntad general deriva necesariamente de la participación del ciudadano sin intervención alguna de interlocutores entre la voluntad manifestada directamente y el resultado de aquélla. En cambio, en el caso de actuar mediante representantes, es el candidato elegido el producto o resultado de la elección correspondiente. Así pues, en la formación de la voluntad el representante se erige en portavoz de la voluntad del representado con un amplio margen de discrecionalidad en el entendimiento y concreción de aquélla.

Tras esta constatación, se aprecia un tratamiento constitucional muy devaluado de las escasas manifestaciones de participación directa de los ciudadanos. De suerte que la genérica atribución al ciudadano de la titularidad del derecho de participación por sí mismo, requiere forzosamente concreción posterior en otros preceptos constitucionales. Deviene por tanto, cuando menos, difícil una interpretación generosa de la participación política directa como criterio hermenéutico respecto del resto del articulado. En efecto, como ha señalado AGUIAR DE LUQUE ${ }^{22}$, no es defendible en los parámetros de la CE de 1978 la existencia de una "vis expansiva" predicable de este precepto, sino, más bien, se hace imprescindible ajustar este artículo a una interpretación más restringida. Que no se trata "de un derecho a que los ciudadanos participen en todos los asuntos públicos, cualquiera que sea su índole y su condición", parece indiscutible, toda vez que estamos en presencia de un derecho de configuración legal. En efecto, lo cierto es que «para participar en los asuntos concretos se requiere un especial llamamiento o una especial competencia si se trata de órganos públicos, o una especial legitimación si se trata de entidades o sujetos de Derecho privado, que la ley puede, en tal caso, organizar" ${ }^{23}$. Es quizá aquí donde se expresa con mayor énfasis por nuestro Alto Tribunal la pertinencia de ajustar el ejercicio del derecho a su previa configuración por la norma de desarrollo, "es lo cierto

22 En efecto, para Aguiar la participación constituye la wexpresión de la filosofia participativa inmanente a la idea democrática", que, ubicada en el art. 9.2, actúa como «norma habilitadora para que los poderes amplíen los cauces participativos en las áreas allí mencionadas", mientras que el artículo 23.1 "contiene tan sólo un ius agendi, un derecho a actualizar la participación en los asuntos públicos", de conformidad con la democraticidad del Estado (op. cit., pág. 660).

${ }_{23}$ STC 51/1984, de 25 de abril, BJC 37, pág. 720. 
-indicará el TC - que ese derecho constitucional que a los ciudadanos se atribuye para participar en los asuntos públicos, ha de ejercitarse -obvio es decirlo- adecuadamente a las previsiones que la normativa en cada caso establezca, previsiones que en lo que aquí y ahora importa están incluidas en la Ley Orgánica» ${ }^{24}$. Es precisamente esta obviedad la que resuelve cualquier duda interpretativa.

No obstante, es posible adoptar una posición matizada de este precepto. Como ha puesto de manifestado GARRORENA ${ }^{25}$, junto al imprescindible carácter de los partidos no se puede olvidar «la congénita vocación expansiva de tales formaciones; porque una democracia donde los múltiples espacios en que se realiza la condición plural de la sociedad (...) sean ocupados por los partidos hasta intentar convertirlos en meros campos de juego a los que trasladar su competencia será siempre una democracia empobrecida, degradada en su condición de tal a una pluralidad de un solo nivel y de sólo tres o cuatro efectivos participantes" ${ }^{26}$.

Por su parte, un análisis de la jurisprudencia constitucional no arroja mayor luz sobre la interpretación del artículo 23.1 CE. Nuestro Alto Tribunal se ha limitado a reconocer el derecho fundamental contenido en el artículo 23 en sus dos ámbitos de sufragio activo y pasivo pero sin profundizar más en el derecho a la participación "directamente" ${ }^{27}$. Quizá una posible explicación pasaría por el escaso número de recursos ante el TC planteados en relación con la legislación de desarrollo de los procedimientos de participación directa o derivados de su aplicación. Razón és-

24 Autos de 16 de enero y 18 de septiembre de 1985, correspondientes a los recursos promovidos contra acuerdos de la Mesa del Congreso de los Diputados inadmitiendo a trámite proposiciones de ley de iniciativa popular sobre pensiones de jubilación para administradores familiares. BJC 54/55, pág. 1380.

25 A. Garrorena Morales, "El Estado Español...», op. cit., pág. 142.

26 A. Garrorena Morales, ibidem, pág. 141. Perspectiva más proparticipativa que se justifica afirmando "que el proceso de poder en una sociedad democrática supone no sólo una comprensión plural de ésta, sino además una constante relación de participación en competencia entre tal pluralidad de individuos y de grupos. De este modo, las decisiones públicas se adoptan a través de la dialéctica - del diálogo de argumento y de interés- de todos los participantes $y$, en consecuencia, desde la participación".

${ }_{27}$ STC 76/1987, de 25 de mayo, BJC 74, pág. 834. Ciertamente el Tribunal Constitucional reconoce la necesaria interpretación de nuestra Carta Magna en el sentido más favorable al ejercicio y disfrute de los derechos fundamentales, pero hace especial hincapié en el proceso electoral. En efecto, ratifica la centralidad del derecho de sufragio activo y pasivo en la legitimación democrática del ordenamiento apuntando cómo han de urecibir un trato especialmente respetuoso y favorable", pero apenas incorpora mención alguna a los procedimientos de participación política directa sin intermediación de los partidos. 
ta que justifica cómo los pronunciamientos del TC se han producido instados por recursos de amparo en vulneración del apartado $2 . .^{\circ}$ de este artículo y casi exclusivamente a raíz de contenciosos surgidos entre partidos políticos y representantes de éstos.

Ciertamente el apartado $2 .^{\circ}$ del artículo 23 prescribe el acceso en condiciones de igualdad a los cargos públicos que es extensible también a la permanencia en ellos hasta que agoten su plazo salvo comportamiento punible ${ }^{28}$. Pero como ha tenido ocasión de señalar nuestro Alto Tribunal, "los representantes dan efectividad al derecho de los ciudadanos a participar $-y$ no de ninguna organización como el partido político-, y que la permanencia de los representantes depende de la voluntad de los electores que la expresan a través de elecciones periódicas, como es propio de un Estado democrático de Derecho y no de la voluntad del partido político. En definitiva, y sin perjuicio de las incompatibilidades que pueda regular la ley, el cese en el cargo público representativo al que se accede en virtud del sufragio no puede depender de una voluntad ajena a la de los electores, y eventualmente a la del elegidon ${ }^{29}$. A partir de las anteriores afirmaciones podemos apuntar como característica esencial de este derecho de participación política, cómo "se otorga a los ciudadanos en cuanto tales" $y$, por tanto no es predicable de las personas jurídicas ni de otros entes o sujetos ${ }^{30}$.

Ahora bien, ante posiciones doctrinales tan divergentes como las apuntadas con anterioridad y a falta de mayor concreción en los pronun-

${ }_{28}$ La reciente STC 119/1990, de 21 de junio, recogiendo la jurisprudencia del Tribunal Europeo de Derechos Humanos (Sentencia de 2 de marzo de 1987, asunto Mathieu-Mohin y Clerfayt), indica cómo "los requisitos que señalen las leyes para el acceso a los escaños parlamentarios "no deben contariar la libre expresión de la opinión del pueblo en la elección del cuerpo legislativo" ". BJC 111, pág. 144.

${ }_{29}$ STC 5/1983, de 4 de abril, BJC 23, pág. 234. A mayor abundamiento, la STC 10/1983, BJC 23, ha señalado que «la vulneración que resulta del hecho de privar al representante de su función les afecta, sin embargo, a todos simultáneamente y es también una vulneración del derecho del representante a ejercer la función que le es propia, derecho sin el que, como es obvio, se vería vaciado de contenido el de los representados (...). Al reaccionar contra el acto que lo expulsa de su función, el representante no defiende, por tanto, sólo un derecho propio, pero tampoco, en modo alguno, un derecho ajeno, pues la finalidad que persigue es justamente la de restaurar la unidad de voluntad en que la representación consiste (...). Implica también el de no ser removidos de los cargos o funciones públicos a los que se accedió si no es por causas y de acuerdo con procedimientos legalmente establecidos".

3o STC 51/1984, de 25 de abril, BJC 37, pág. 720. También STC 23/1983, de 25 de marzo, BJC 24, pág. 386 , en clara referencia a los sindicatos. 
ciamientos de la jurisprudencia constitucional, parece quizá más indicado adoptar una actitud de prudencia ante el artículo 23.1 CE, sin perjuicio de proponer una línea favorable a la interpretación amplia del contenido del artículo $23 \mathrm{CE}$. No podemos olvidar que estamos en presencia de un derecho fundamental que goza del mayor nivel de protección constitucional y que se deriva de la proclamación del Estado español como democrático, fórmula ésta no acabada, que debe ser percibida como momento constante en el que se tiende a alcanzar mayores niveles de democratización de la sociedad. Por tanto, entendemos que el derecho a la participación posee una enorme virtualidad transformadora de la sociedad actual, en la medida en que el efectivo reconocimiento de este derecho a la participación política, intensamente relacionado con el derecho a la participación en el resto de las esferas de la vida en sociedad, se integra en un núcleo esencial del Estado democrático y social que no puede ser restringido ni limitado más allá del propio ordenamiento jurídico. De modo tal que impide de una parte la existencia del Estado democrático no representativo, en la medida que no tiene cabida en nuestro sistema político un modelo de Estado democrático distinto del Estado democrático representativo. De otra, porque la CE actúa como un límite que impide al legislador restringir el derecho de participación.

Si por un momento abordamos el objeto de esta reflexión desde la vertiente del derecho subjetivo del ciudadano como derecho fundamental, qué duda cabe que una de las características del moderno Estado democrático, es la continua tensión entre el ejercicio de los derechos fundamentales por el ciudadano y su regulación por el legislador. A partir de aqui es factible propugnar una mayor profundización de la democracia en el Estado; ahora bien, no podrá llevarse ésta sino a través de una interpretación flexible de las normas que garantice la materialización de los derechos subjetivos de los ciudadanos. Esfuerzo que se debería potenciar en el reconocimiento real de los derechos que favorecen la participación ciudadana en la esfera política. Sin embargo, aunque pueda resultar paradójico, en el caso del derecho a la participación en los asuntos públicos no concurre esta tensión sino muy amortiguada. La razón estriba en que tanto en la CE como por parte del legislador, la actitud que se ha adoptado respecto a las instituciones de democracia directa es extremadamente restrictiva. Como se ha constatado reiteradamente, si la redacción del artículo $23 \mathrm{CE}$ puede en principio hacernos pensar en un equilibrio entre ambas formas de participación, la realidad constitucional confirmó una clara descompensación en favor de la democracia representativa. Bien es cierto, y así se ha señalado, que la enumeración que se contiene en la Constitución de las instituciones de democracia directa es amplia, pero es igualmente cierto que no basta con su sola presencia en el texto fundamental, sino que se hace preciso también analizar su alcance real y contenido efectivo. 
De cualquier forma, la expresión "directamente" encierra una cierta polémica que no se resuelve simplemente con la enumeración de los distintos tipos de referéndum o iniciativa legislativa popular recogidos por la Constitución como formas concretas de la participación directa de los ciudadanos. La presencia de estas instituciones constituyen una acertada opción del constituyente, pero la posición en que aquéllas se encuentran respecto a las formas de participación a través de representante distan mucho de ser equivalentes. Hay un indiscutible "sentimiento de accesoriedad" respecto de las formas representativas. La clave habría que buscarla en la proclamación de los partidos políticos como «instrumento fundamental" de la participación. Porque la CE no afirma que sea el único instrumento, pero tampoco queda suficientemente explicitada la existencia de otros instrumentos de igual fundamentalidad. Es, pues, una afirmación sumamente tajante que no tiene correspondencia en derecho comparado, que confirmaba el énfasis que se pretendía poner en tal reconocimiento y que dejaba al resto de las formas participativas en un segundo lugar y sujetas a un considerable rigorismo normativo ${ }^{31}$.

Ciertamente, la tensión entre parlamentarismo y democracia semidirecta señalada por GARRORENA ha estado presente en todo momento en la mente del constituyente. Pero si bien es cierto que ya en momentos anteriores de nuestra historia constitucional se ha podido apreciar, ha cobrado nueva intensidad con objeto de la elaboración de la Carta Magna de $1978^{32}$. El reciente pasado -referéndum franquista-, así como un concepto del parlamentarismo harto purista, "celoso a la hora de preservar la primacía institucional del Parlamento" ${ }^{33}$, ha pesado en contra de las instituciones de participación directa del ciudadano.

Incluso el propio Tribunal Constitucional se ha pronunciado sobre el protagonismo indiscutible de los partidos en nuestro sistema político como principal instrumento de configuración de la voluntad popular al señalar cómo "la participación en los asuntos públicos, a que se refiere el artículo 23, es en primera línea la que se realiza al elegir los miembros de las Cortes Generales, que son los representantes del pueblo, según el artículo 66 de la Constitución, y puede entenderse asimismo que abarca

31 M. Ramirez, "Democracia Directa y Constitución: problema y desarrollo legislativo", en Ramírez (ed.), El desarrollo de la Constitución Española de 1978, Zaragoza, 1982, op. cit., pág. 19.

32 A. Garrorena Morales, "El Estado español...», op. cit., pág. 143.

33 A. Garrorena Morales, ibidem, pág. 146. Considera que este sentimiento ha sido sustentado por la mayoría de las fuerzas parlamentarias. Actitud ésta -añade- que ha llevado al constituyente a «una interesada falta de imaginación de que el sistema representativo hace gala cuando se trata de idear soluciones que permitan vitalizar la posición política de los ciudadanos" (op. cit., pág. 129). 
también la participación en el Gobierno de las Entidades en que el Estado se organiza territorialmente, de acuerdo con el artículo 137 de la Constitución ${ }^{34}$.

Sin embargo, también es cierto que el propio Tribunal ha hecho especial hincapié en la titularidad del derecho, así como en las conexiones que se establecen entre sus titulares y los partidos hasta el punto de destacar cómo «la participación directa que en los asuntos públicos ha de corresponder a los ciudadanos es la que se alcanza a través de las consultas populares previstas en la propia Constitución (arts. 92, 149.1.32, $150.1,152.2,167.3$ y 168.3), procedimientos éstos en los que habrán de hacerse presentes, sin duda, los partidos $y$, en general, las agrupaciones políticas, mas no como titulares del derecho mismo a la participación, sino en lo que a los partidos políticos se refiere, como instrumentos fundamentales que son para hacerla posible, concurriendo, como la Constitución quiere, a la formación y manifestación de la voluntad popular» ${ }^{35}$.

\section{LA PARTICIPACIÓN COMO PRINCIPIO ORIENTADOR DE LA ACCIÓN DEL ESTADO (ARTÍCULO 9.2 CE)}

El artículo 9.2 CE es cuando menos un ambicioso precepto en el que conviven dos objetivos: la consecución de la igualdad y la libertad, de un lado, y posibilitar la participación ciudadana en diversos ámbitos, de otro. Es aquí donde, como ha señalado M. RAMíREZ ${ }^{36}$, se ubica la clave para encontrar "el auténtico alcance" del precepto que puede dar cabida desde "una interpretación progresista del resto del ordenamiento constitucional» hasta quedar en simple "letra muerta». Temor éste que ha sido apuntado por GARRIDO FALLA ${ }^{37}$, quien estima que "estamos ante un precepto de carácter programático cuya operatividad práctica es muy escasa; porque la esencia de la norma jurídica no está tanto en fijar los objetivos que se pretende alcanzar, cuanto en instrumentar los me-

${ }^{34}$ STC 51/1984, de 25 de abril, BJC 37, pág. 720.

35 STC 63/1987, de 20 de mayo, BJC 74, pág. 796.

${ }_{36}$ M. Ramírez, "La Participación...», op. cit., pág. 45. En este sentido ha señalado M. Ramírez cómo uel valor programático de este núm. 2 del artículo 9 quedará siempre condicionado por dos circunstancias: el predominio de una y otra mayoría en el juego político de nuestro país y el marco social, jurídico y económico que la misma Constitución establece en otras partes de su articuladon.

37 Garrido Falla, "Comentario al artículo 9.2», en Comentarios a la Constitución, op. cit., pág. 45. 
dios para conseguirlos". Sin embargo, la correcta interpretación del alcance de este precepto es polémica en la doctrina. Así, en los primeros años de la democracia se produjo una abundante discusión doctrinal a partir de la argumentación en favor de la capacidad transformadora que se contiene en el 9.2 CE en conexión con el Preámbulo de la Constitución ${ }^{38}$. También ha sido considerada inadecuada la equiparación que se efectúa en este precepto entre los individuos y los grupos, aunque resulte innegable la función de intermediación que realizan éstos, ya que reflejan la diversidad y pluralismo de la sociedad, contribuyen a la defensa de sus derechos y socializan a los individuos en el respeto de los intereses de los demás ${ }^{39}$.

Pero el aspecto más relevante del artículo 9.2 CE para esta reflexión lo constituye la ambiciosa propuesta participativa del constituyente. Ciertamente, este precepto constituye la otra cara de la moneda imprescindible para otorgarle consecuencias jurídicas al derecho de participación. En efecto, en relación con los principios ya postulados en el 1.1 CE como valores superiores del ordenamiento jurídico, se pretende su vigencia y efectividad, además de facilitar la participación como concreción de la proclamación del Estado social y democrático. Este mandato constitucional implica, pues, la asunción por parte de los poderes públicos del deber de "facilitar la participación" ciudadana más allá del marco político, extendiendo este alcance al resto de los ámbitos económico, cultural y social. Compromiso que impone "remover obstáculos" y "promover" actuaciones concretas para posibilitar que pueda ser real tal participación.

Ahora bien, no quedaría completa la descripción de este precepto sin hacer referencia a la necesaria concreción del mismo a través del establecimiento de algunas conexiones entre el $9.2 \mathrm{CE}$ y otros artículos de nuestra Norma Fundamental que delimitan y condicionan su virtualidad. El carácter programático del Título Preliminar no ofrece duda alguna, razón ésta que nos obliga a acudir a los procedimientos específicos regulados en otros Títulos de la Carta Magna. Además, el análisis del 9.2 CE se encuentra igualmente condicionado por el sentido de la jurisprudencia constitucional.

38 A. Pérez Luño, Derechos Humanos, Estado de Derecho y Constitución, págs. 229 y ss. E. DíAz, entre otras, Legalidad-legitimidad en el socialismo democrático, págs. 125 y ss., Madrid, 1977; Estado de Derecho y Sociedad Democrática, 1981. E. Álvarez Conde, El Régimen político español, pags. 37 y ss. A. Garrorena MoRALES, El Estado español como Estado Social y Democrático de Derecho, págs. 201 y ss.

39 A. Garrorena Morales, "El Estado Español...", op. cit., págs. 132-33. 
En primer lugar, es preciso hacer referencia al reconocimiento efectuado por la CE de sujetos con capacidad participativa en los diversos órdenes de la sociedad moderna. Así no sólo partidos políticos y asociaciones pueden llevar a cabo la participación, también sindicatos y Colegios Profesionales tienen un marcado protagonismo en el ámbito laboral, sin olvidar las organizaciones de consumidores.

Sin embargo, el reconocimiento de esta pluralidad de sujetos ha de ser necesariamente complementada con procedimientos específicos que permitan la satisfacción de los intereses correspondientes, impidiendo una inmediatez en la actuación sin previo desarrollo normativo o actuación administrativa ${ }^{40}$.

Por otra parte, hay que reseñar cómo los pronunciamientos de nuestro Alto Tribunal relativos al artículo 9.2 CE dejan nuestra indagación bastante mermada, ante el escaso material que aquéllos nos proporcionan. La mayor parte de las sentencias dictadas por el Tribunal Constitucional en cuyos fundamentos se contenía el precepto estudiado, se derivan del ámbito socioeconómico y originariamente se habian suscitado en conflictos laborales. Sin embargo, no cabe duda que el marco de este segundo apartado del artículo $9 \mathrm{CE}$ es mucho más amplio: vida política, económica, cultural y social.

En realidad, ha sucedido que el tratamiento homogéneo de la participación en los distintos ámbitos otorgado por el artículo 9.2 CE no sólo se concreta y mediatiza en otros preceptos constitucionales, sino que su eficacia práctica queda muy devaluada, en tanto que por el legislador posterior así como los operadores jurídicos no se impulse su virtualidad. Cierto es que no podemos articular una posible respuesta concisa en el momento actual, pero a falta de una línea jurisprudencial proparticipativa, sólo podemos constatar el desigual tratamiento por los diferentes operadores en el mundo del derecho del artículo 9.2 $\mathrm{CE}$, más allá de su función programática en la interpretación y complementación de otros principios y derechos de reconocimiento constitucional ${ }^{4}$.

40 "La ley garantizará el derecho a la negociación colectiva laboral» (art. 37 CE), "los poderes públicos promoverán las condiciones para la participación... de la juventud" (art. 48).

${ }^{41}$ En ese sentido, la apelación al art. 9.2 como obligación que al Estado impone de promover "las condiciones para que la igualdad de los individuos $y$ los grupos sean reales $y$ efectivas", encuentra en la mayoría de las ocasiones su complemento en la igualdad (STC 81/1982, BJC 21, pág. 71). 
Quizá una posible línea que facilite una mayor integración del artículo 9.2 CE en el ejercicio de los derechos fundamentales sea la señalada entre nosotros por GARRORENA. En efecto, tomando como punto de partida la transcripción casi completa realizada por el constituyente español del artículo 3 de la Constitución italiana en una teórica y criticable igualdad formal (art. $14 \mathrm{CE}$ ) y material (art. 9.2 CE), la experiencia derivada de la jurisprudencia constitucional nos muestra cómo se ha potenciado una interpretación y aplicación "generosa" de la libertad impropiamente definida como jurídico-formal recogida en el artículo $14 \mathrm{CE}$, impidiendo de este modo llevar a cabo todas las virtualidades del artículo $9.2 \mathrm{CE}$. Pues aunque no parece fácil sostener que este último precepto pueda contener "pretensiones jurídicas" que directamente puedan ser esgrimidas por los ciudadanos ${ }^{42}$, no resultaría imposible su directa aplicación en la fundamentación jurídica del fallo por los tribunales. Incluso su recepción generalizada en la jurisprudencia constitucional incidiria en la orientación futura del legislador y en la actuación cotidiana de los poderes públicos ${ }^{43}$.

Por otra parte, habria incluso que precisar distintos niveles derivados del reconocimiento constitucional del Estado social a través de la participación directa del ciudadano y de la participación mediatizada a través de representantes que impropiamente denominamos como tales aquí y que se concretarian en asociaciones, corporaciones y otros grupos intermedios que de diversos modos gestionarían, ante entidades públicas o incluso privadas, la satisfacción de intereses y exigencias reconocidas constitucionalmente, aunque con menos nivel de protección y difusamente distribuidas por el texto constitucional. Además, dentro de este elenco de instrumentos participativos en la esfera social, económica y cultural no podemos olvidar el reconocimiento expreso del que son objeto determinados grupos intermedios (Colegios Profesionales, Sindica-

${ }_{42}$ Como ha señalado Enrique ÁlvaAEZ CONDE, la necesaria interpretación del artículo 9.2 "dentro de las coordenadas del Estado social de derecho" no es obstáculo para constatar "su virtualidad transformadora y su valor hermenéutico" («E) régimen político español», op. cit., pág. 45).

${ }^{43}$ A. Garrorena Morales, "El Estado Español...", op. cit., pág. 67: "Es esperable que la eficacia del artículo 9.2, a efectos jurisprudenciales, se haga explícita tanto más que en su capacidad para fundamentar inmeditamente un fallo (lo cual será posible, y aun estimable, siempre que la concreción individual del supuesto o las condiciones de su planteamiento lo permitan) en su valor para servir de soporte a determinadas "recomendaciones al legislador" dirigidas a recordar a éste la exigencia constitucional de producir ciertas leyes y de producirlas en el sentido más adecuado a la remoción de determinados obstáculos sociales; probablemente es lícito pensar incluso que es precisamente aqui donde el Tribunal tendría las mayores y mejores oportunidades para ir definiendo, con adecuado vuelo general, una ponderada doctrina sobre el alcance y contenido del artículo 9.2\%. 
tos) más allá del derecho genérico de asociación (art. $22 \mathrm{CE}$ ) reconocido constitucionalmente.

\section{LA DIFÍCIL CONFIGURACIÓN DE UN DERECHO A LA PARTICIPACIÓN POLITICA DIRECTA DE LOS CIUDADANOS}

Como hemos podido constatar en las páginas anteriores de la breve descripción de las formas participativas recogidas constitucionalmente podemos obtener algunas conclusiones que nos permitirán si acaso una aproximación a la configuración de un derecho genérico a la participación.

En primer lugar, hay que destacar el amplio elenco de instrumentos teóricos contenidos en la CE para posibilitar la participación ciudadana en los diversos órdenes de la vida estatal. Ahora bien, esta serie de mecanismos ni encuentra su origen en un mismo fundamento ni tampoco se ubica en el texto constitucional del mismo modo; de ambas consideraciones se derivan algunas otras cuestiones que requieren mayor precisión.

En efecto, al comienzo de esta reflexión constatábamos la necesaria interpretación sistemática de la cláusula de Estado democrático indisolublemente unida a las de Estado de derecho y al Estado social. Pues bien, la recepción de éste último introduce en nuestro ordenamiento constitucional nuevas formas de participación que rebasan los límites del Estado democrático. Así, tomando como punto de partida el artículo 9.2 CE podemos formular una aproximación al derecho de participación que si bien en el ámbito político en sentido estricto tendría su fundamento en el artículo $23 \mathrm{CE}$, en los restantes espacios sociales encuentra su reconocimiento en diversos preceptos constitucionales distribuidos en varios títulos de la CE.

De este modo, y a efectos sistematizadores, podemos adelantar una hipótesis interpretativa que tiene como punto de partida la proclamación de "la participación de todos los ciudadanos en la vida política, económica, cultural y social" (art. 9.2 CE), como corolario, la responsabilidad de los poderes públicos para remover los obstáculos e impedimentos que surjan, y como finalidad la participación real del ciudadano. A partir de aqui se hace necesario diferenciar dos esferas de participación ciudadana en el texto constitucional. De un lado nos encontramos con la participación política, que entroncaría directamente con la tradición jurídica democrática, en tanto que derecho político del ciudadano a partici- 
par en la vida política por si o mediante representante (art. $23 \mathrm{CE}$ ). De otra, el reconocimiento del ciudadano o de los grupos (organizados o no, en los que se pueda integrar) como parte necesaria, en algunos casos, en los procesos de toma de decisiones, bien a nivel inter-particulares (arts. 37, 129.2 CE), bien en las relaciones entre particulares y poderes públicos (art. 129.1 CE), que se concreta en fenómenos asociativos y corporativos, sin olvidar que puede actuar como parte legitimada ante la Administración Pública (art. 105) o la Administración de Justicia (art. $125 \mathrm{CE}$ ) y que encuentra su fundamento en la proclamación del Estado social concebido como intervención, gestión y planificación de las políticas públicas.

Indudablemente, estas dos subesferas del derecho de participación no se encuentran en situación de identidad entre sí respecto a su virtualidad, ni siquiera respecto a su tratamiento constitucional o normativo. Si bien es cierto el valor normativo de toda la CE (art. 9.1), nada impide que los derechos políticos de participación gocen de una mayor protección por el ordenamiento constitucional. No ocurre asi con los derechos de participación que se derivan del reconocimiento del Estado social, que son objeto de una muy inferior tutela; además, no pueden ser objeto de igual tratamiento formas de participación en la Seguridad Social o en la Administración de Justicia que la que se efectúe a través de Colegios Profesionales o de asociaciones de consumidores. No podemos olvidar tampoco a los efectos de esta exposición que aquéllos (Colegios o asociaciones) tienen un referente en su actuación en el artículo 53.3 que actúa como límite insalvable a la hora del efectivo ejercicio de los derechos, principios, garantías y cautelas que se encuentran recogidos en el Capítulo III, Título I, de la CE, bajo la criticable denominación de "Principios rectores". De tal modo que en defecto de ley que regule estos "principios", en el momento actual sólo podría propugnarse una interpretación coherente de los mismos con el artículo 9.2 CE a través del entendimiento extensivo y generoso de este último precepto que, dotado de un carácter finalista, impulsara la actuación de todos los mecanismos participativos previstos en la $C E$, pese a que dentro de cada una de estos ámbitos no existe tampoco un tratamiento uniforme de los diversos instrumentos participativos.

Así, en el contexto estricto de la participación política podemos constatar cómo el protagonismo indiscutible de los partidos políticos, buscado a propósito por casi todas las fuerzas políticas durante el debate constituyente, deja en un plano muy residual las formas de participación directa de los ciudadanos. Ciertamente, la impresión inicial que nos ofrece el artículo 1.1 CE es que no cabe en el ordenamiento constitucional español un Estado democrático distinto al modelo democrático representativo. De tal modo que los partidos políticos y la representación actúan a la vez como contenido esencial del modelo de sistema político y como límites ad extra del propio sistema. Parámetros básicos que nos permiten 
afirmar cómo el modelo de estructura democrática y participativa del Estado español es el de la democracia representativa, no siendo posible dentro del texto fundamental de 1978 ningún otro posible modelo de Estado democrático fuera del Estado democrático representativo ${ }^{44}$.

Sin embargo, pese a la contundencia de las anteriores afirmaciones queda sin resolver la virtualidad del reconocimiento constitucional del "derecho a participar en los asuntos públicos, directamente". Incluso podría plantearse el carácter superfluo de tal precepto, aunque desde la perspectiva que sostenemos en este trabajo, es factible entender que la plasmación constitucional de la participación directa deja una puerta abierta al legislador, a los tribunales e incluso a los poderes públicos en general, para en un futuro no lejano facilitar la efectividad de la participación directa de los ciudadanos en los asuntos públicos.

Podríamos concretar, por último, un poco más el alcance de los instrumentos participativos en el ámbito social, cultural y económico indicando que en este contexto no se ha erigido una vía como esencial frente a otras residuales como sucede en el marco de la participación política. Es más, tanto de los debates constituyentes como de la redacción definitiva de la Norma Fundamental se deduce una actitud menos cauta y recelosa hacia estos instrumentos de participación que frente a los institutos de democracia directa. Ahora bien, el alcance de la participación en uno y otro caso es distinto $y$, no podemos olvidar cómo de la ubicación sistemática de los preceptos en la CE y, en concreto del artículo 53.3, se desprende un claro freno (límites hoy por hoy) al ejercicio de los "principios rectores", a la alegación ante los tribunales de los derechos que se reconocen en la esfera social, cultural y económica de los ciudadanos. En este sentido se ha reivindicado de aquéllos "la significación de "disfrute". Pero junto a esta interpretación, el texto fundamental incorpora, bien explícitamente (art. 47, 48, 51), bien indirectamente por medio del art. 129.1, la otra comprensión que literal o lingüísticamente recibe el término "asociarse, colaborar, cooperar, intervenir" " ${ }^{45}$. Sin olvidar, por último, que en la mayoría de los casos se vehiculan mediante la intermediación de corporaciones, asociaciones y otros institutos que en gran medida representan a los individuos y colectivos sectorialmente.

${ }_{44}$ En este sentido entiende LuCAs Murillo que «solamente la representación democrática hace posible, por tanto, la construcción del edificio constitucional, la limitación del poder político y la salvaguardia de los derechos fundamentales" (Problemas constitucionales de la representación política, Pontignano-Siena, 1990, pág. 5).

${ }_{45}$ G. RuIz-Rıco RuIz, Los principios rectores de la política económica y social en la Constitución Española de 1978, Universidad de Granada. 